\title{
A política fundiária nos planos locais de habitação: entre a demanda terra e o direito de propriedade
}

\author{
Land policy in local housing plans: between the demand \\ for land and property right
}

\section{Joana Aparecida Zavaglia Mascarenhas Torres Ribeiro Tomás Antonio Moreira}

Joana Aparecida Zavaglia Mascarenhas Torres Ribeiro Pontifícia Universidade Católica de Campinas Campinas - SP - Brasil

\section{Tomás Antonio Moreira} Universidade de São Paulo São Carlos - SP - Brasil

Recebido em 19/04/14 Aceito em 06/10/14

\section{Resumo

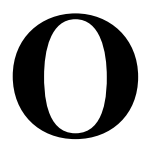

s esforços jurídico-institucionais para a construção de cidades mais justas deram ao Brasil uma importante chavepara a reversão dos problemas sociais urbanos: a função social da terra. Este conceito tem uma importância estratégica na política habitacional: estabelecer a base das intervenções em habitação. No contexto atual da Política Nacional de Habitação, como esse conceito é incorporado nos planos locais de habitação? Frente a esta colocação, procura-se discutir o espaço da terra na política habitacional da cidade de Campinas, por meio da análise do Plano Municipal de Habitação. O debate é realizado sob três perspectivas de análise: o quadro da precariedade habitacional no município, as necessidades fundiárias da política habitacional e as medidas previstas para atendimento destas necessidades. A análise evidenciou que a terra para moradia compreende um potencial fundiário privado e, neste sentido, a política fundiária é entendida como uma política que visa à limitaçãodo direito privado da propriedade em benefício do interesse coletivo. Esta política, no entanto, tem se revelado ineficaz, visto que o grau das intenções a respeito do cumprimento da função social não se traduz em de ações concretas.

Palavras-chaves: Gestão urbana. Política fundiária. Política habitacional. Função social da terra. Direito à propriedade.

\begin{abstract}
Legal and institutional efforts to make fairer cities have given Brazil an important key to reverse its urban social problems: the land social function.This concept hasanstrategic importance in housing policy: to establish the foundation forhousing interventions. How is this concept embedded in local housing plans, within the current context of Brazil's National Housing Policy? With that in view this paper discusses the place of land in the housing policy of the municipality of Campinas, by examining its Municipal Housing Plan. The discussion is conducted from three perspectives: the situation of housing precariousness in the municipality, the land needs of the housing policy, and the measures foreseen to meet those needs. The analysis revealed that the land foreseen for housing comprises potential private land. In this sense, land policy is understood as a policy aimed at limiting the private property law to the benefit of the collective interest. This policy, however, has proven to be ineffective, since the intention to fulfil the social function does not translate into concrete policy actions.
\end{abstract}

Keywords: Urban management. Land policy. Housing policy. Land social function. Right to property. 


\section{Introdução}

No campo dos estudos e da formulação das políticas de habitação social, a terra urbana sempre foi entendida como um componente essencial a ser enfrentado. Condicionante da localização que qualifica o acesso aos benefícios decorrentes do processo formal de urbanização, a terra urbana é base determinante das ações que efetivam tais políticas, sobretudo das que se associam à produção de moradias (ROLNIK; CYMBALISTA; NAKANO, 2008; LADIS; MCCLURE, 2010; GOETZ, 2012). Apesar de haver consenso sobre a questão, as políticas habitacionais empreendidas no Brasil raramente trataram desse componente de maneira adequada (VALENÇA; BONATES, 2010). Pelo contrário, foram fortemente influenciadas pela problemática fundiária, tendo contribuído para agravar a segregação e as desigualdades socioespaciais presentes nas cidades (SILVA, 1997).

Desde o período de atuação do Banco Nacional de Habitação (BNH) e do Sistema Financeiro da Habitação (SFH), a partir de meados dos anos 1960, a viabilização da terra para programas habitacionais foi delegada aos municípios e aos agentes promotores da produção de moradias (NASCIMENTO NETO; MOREIRA; SCHUSSEL, 2012). Políticas de solo que pudessem contribuir ou dar suporte às ações habitacionais e propiciar a inserção da moradia e o acesso a equipamentos e serviços sociais urbanos foram pautadas em operações de desapropriação ou compra direta de terrenos de baixo custo, localizados em áreas distantes de regiões já consolidadas e nem sempre adequadas, o que exigiu investimentos públicos adicionais em infraestrutura e equipamentos urbanos. Além de distantes e precários, os terrenos viabilizados contribuíram para a abertura de novas frentes de expansão urbana e de valorização imobiliária, o que encareceu os preços fundiários, aprofundando de maneira paradoxal a problemática da obtenção de terra pelo poder público e pela população de baixa renda (NEEDHAM; VERHAGE, 1998; SILVA, 1997).

Tanto emâmbito nacional quanto no do planejamento e da gestão urbana municipal, a prática da política habitacional ficou caracterizada por um quadro de ausência de políticas de solo redistributivas ou de ações que permitissem ampliar o acesso a terra. Com a falência do $\mathrm{BNH}$, em 1986, esse quadro se acirrou, acompanhado pela queda expressiva dos investimentos no setor habitacional e pelo esvaziamento na formulação e implantação de políticas públicas (ROLNIK; CYMBALISTA; NAKANO, 2008). Apesar de certa ausência na definição de políticas, os quase vinte anos pós-BNH preparam as bases conceituais que permitiram estruturar o retorno de uma nova política nacional de habitação, bem como conceber o ideário que formalizaria a construção de uma política fundiária e de planejamento urbano para o país (ROLNIK, 2006).

Importantes transformações no campo jurídicoinstitucional foram lançadas, as quais intencionavam, pelo menos em discurso, reverter os graves problemas da polarização e segregação socioespacial intrínsecas ao padrão de desenvolvimento urbano brasileiro (BONDUKI, 2011; MOREIRA, 2012; NASCIMENTO NETO; MOREIRA; SCHUSSEL, 2012).

A Constituição Federal de 1988 e o Estatuto da Cidade de 2001 (BRASIL, 2001) instituíram um marco ao reconhecer o direito à cidade e à moradia como princípios sociais fundamentais. Em termos de política urbana, estabeleceram novos mecanismos para planejar o desenvolvimento das cidades, definindo-se instrumentos urbanísticos que objetivassem, em princípio, viabilizar os direitos referidos e criar canais de participação que pudessem mediar as relações e as decisões estabelecidas entre o Estado e os agentes envolvidos no processo de produção do espaço urbano (SANTOS JUNIOR.; MONTANDON, 2011).

A Constituição buscou alavancar um processo de descentralização das competências governamentais, a partir do qual os municípios passaram a assumir autonomia na definição, condução e execução de suas políticas públicas. Reafirmou o princípio da função social da propriedade, sob o qual o Estatuto da Cidade passou a se apoiar, definiu diretrizes para seu cumprimento e estabeleceu o Plano Diretor municipal como instrumento básico dos conteúdos da política urbana.

Em 2003, a criação do Ministério das Cidades (MCIDADES) e a composição de secretarias nacionais permitiram, ainda, institucionalizar novas políticas, inicialmente voltadas à construção de um pacto para enfrentamento do quadro urbano e habitacional no Brasil. Estruturava-se nesse contexto a Política Nacional de Habitação (PNH) com um conjunto de instrumentos que buscavam integrar os diferentes níveis de governo e concentrar recursos expressivos para sua concretização. Com sua aprovação, em 2004, ficaram dispostas as "novas" bases institucionais e conceituais que possibilitariam o equacionamento

218 Ribeiro, J. A. Z. M. T.; Moreira, T. A. 
das necessidades habitacionais do país (VALENÇA; BONATES, 2010).

Preconizando-se a gestão participativa e democrática, adotando-se o direito à moradia como direito fundamental e a moradia digna como vetor de inclusão social, a articulação com a política urbana e a integração às ações das demais políticas sociais e ambientais foram estabelecidas como princípios fundamentais da PNH (MINISTÉRIO..., 2008c). A partir desses princípios, a gestão e o controle social, o projeto financeiro e a política fundiária urbana ficaram conceitualmente definidos como eixos centrais para sua implantação (BONDUKI, 2009).

Em relação ao eixo da política fundiária, a $\mathrm{PNH}$ (MINISTÉRIO..., 2008c) estabeleceu como princípios a implementação dos instrumentos e das diretrizes gerais da política urbana dispostos pelo Estatuto da Cidade, visando garantir o cumprimento da função social da cidade e da propriedade, e o melhor ordenamento e controle do uso do solo, de forma a combater a retenção especulativa da terra e viabilizar seu acesso pela população de baixa renda (MINISTÉRIO..., 2008c; MACEDO, 2008).

Já o projeto financeiro foi estabelecido com a estruturação do Sistema Nacional de Habitação (SNHAB), que passou a definir as formas de articulação entre os diferentes níveis de governo e os demais agentes públicos e privados envolvidos no setor, bem como as regras, os componentes e as linhas de atuação que direcionariam recursos para a implementação da PNH.

O SNHAB se organizou em dois subsistemas: o Sistema Nacional de Habitação de Interesse Social (SNHIS); e o Sistema Nacional de Habitação de Mercado (SNHM). O SNHM teve como objetivo garantir e sustentar a participação do setor privado na produção habitacional, visando ampliar a oferta e facilitar o acesso ao financiamento da habitação pelos setores populares não atendidos anteriormente pelo mercado.

Por sua vez, o SNHIS, instituído pela Lei Federal n. 11.124 (BRASIL, 2005), teve como objetivos integrar os entes federativos e ampliar os recursos federais, estaduais e municipais, visando incrementar os subsídios destinados ao atendimento habitacional das faixas populacionais de mais baixa renda, nas quais se concentra a maior parcela do déficit habitacional brasileiro (MINISTÉRIO..., 2006). Sua regulamentação se articulou à criação do Fundo Nacional de Habitação de Interesse Social (FNHIS), que passou a ser gerido por um conselho correlato, o Conselho Gestor do FNHIS.
Para a implantação do SNHIS e para acesso aos recursos do FNHIS, Estados, Municípios e Distrito Federal foram impelidos a aderir ao Sistema mediante três requisitos: constituir fundo municipal de Habitação de Interesse Social (HIS); instituir respectivo conselho gestor paritário e com representatividade de movimentos sociais ligados à moradia; e elaborar plano de habitação em seu nível de gestão (BRASIL, 2005).

Os municípios, por meio de seus Planos Locais de Habitação de Interesse Social (PLHIS), teriam a responsabilidade de levar adiante os pressupostos da $\mathrm{PNH}$, considerando a moradia como um direito fundamental e como um vetor de inclusão social, e, portanto, como um componente da política urbana (MINISTÉRIO..., 2006).

Embora devessem ser levados a cabo nos PLHIS(s), os pressupostos da PNH para o eixo da política fundiária estariam, no entanto, associados e ainda dependentes de outros instrumentos de política urbana, sobretudo o Plano Diretor e legislações a ele complementares, uma vez que este passou a ser o instrumento básico da política urbano-fundiária após a promulgação do Estatuto da Cidade (CARDOSO; ROMEIRO, 2008).

Referenciando-se nas bases conceituais e instrumentais estabelecidas no cenário exposto, o MCIDADES passou a atuar técnica e financeiramente em duas grandes frentes de trabalho, visando estimular a formulação e implementação do planejamento urbano e habitacional nos Municípios e Estados brasileiros.

A partir de 2005, investiu-se na elaboração dos Planos Diretores, com o objetivo de difundir o princípio da função social da cidade e da propriedade, bem como a construção de pactos socioterritoriais entre os diversos atores e interesses presentes nas cidades, tendo como ponto central o tema da terra urbana e da localização da população de baixa renda no território (ROLNIK, 2006). A partir de 2007, investiu-se na elaboração de planos de habitação nos diferentes níveis de governo, buscando identificar o quadro das problemáticas habitacionais e definir estratégias de ação que permitissem incluir a viabilização da terra para habitação de interesse social (HIS), bem como articular políticas de solo como medida estruturadora para sua produção (DENALDI; LEITÃO; AKAISHI, 2011; MINISTÉRIO..., 2009).

Observam-se nos últimos anos diversos estudos que procuram analisar os resultados das ações desencadeadas pelo MCIDADES nessas duas frentes de busca pela instauração de um novo paradigma de democratização do acesso a terra e à moradia. Nas linhas de pesquisa sobre os Planos 
Diretores, lócus de definição da política urbanofundiária, coloca-se como referência nacional a publicação organizada por Santos Junior e Montandon (2011), destacando-se a análise de Oliveira e Biasotto (2011), que vem mostrar os resultados pouco efetivos dos Planos Diretores elaborados pós-Estatuto da Cidade em se estabelecerem pactos sociais em torno do princípio da função social.

Nas linhas de pesquisa sobre os planos de habitação, as análises se mostram ainda recentes, tendo-se como principais referências os debates levantados por Denaldi, Leitão e Akaishi (2011), Denaldi (2013a, 2013b), Fonseca, Fernandes e Tavares (2013) e Denaldi e Bruno Filho (2013) que focalizam as limitações e perspectivas do processo de formulação dos planos, bem como as formas de tratamento do tema da terra e da precariedade habitacional no planejamento habitacional em âmbito local.

A despeito da ampliação do conhecimento produzido sobre as políticas formuladas no contexto exposto, fazem-se relevantes $o$ desenvolvimento e a difusão de estudos que permitam aprofundar a investigação sobre como a terra urbana tem sido tratada nos instrumentos representativos da nova $\mathrm{PNH}$, sobretudo para que se possa reconhecer avanços ou permanências em relação às políticas empreendidas no passado da política habitacional brasileira. Mas como a questão fundiária vem sendo abordada nos planos de habitação e em que sentido essa abordagem orienta a definição de novas estratégias de ação para o enfrentamento do quadro dos problemas habitacionais? Este artigo busca responder tal questão e insere-se no debate por meio da análise do Plano de Habitação de Campinas, município localizado no interior do estado de São Paulo e sede de sua Região Metropolitana (RMC).

\section{Metodologia}

O município de Campinas teve seu plano de habitação formulado por consultorias técnicas especializadas $^{1}$, coordenadas pela prefeitura local, no âmbito de um processo participativo que envolveu o Conselho Municipal de Habitação, entre os anos de 2010 e 2011. Seguindo-se sugestões dispostas no Guia de Adesão dos municípios ao SNHIS (MINISTÉRIO..., 2008a), o Plano de Habitação apresenta uma estrutura padronizada, que consolida três conteúdos distintos: a metodologia de sua formulação, o

\footnotetext{
${ }^{1}$ Fundação Getúlio Vargas (FGV) e Demacamp Planejamento, Projeto e Consultoria.
}

diagnóstico do setor habitacional e as estratégias de ação para sua implementação.

Para a reflexão pretendida, foram analisados tanto os documentos do Diagnóstico Habitacional quanto os relativos às Estratégias de Ação (PREFEITURA..., 2011). A análise considerou as diretrizes técnicas normatizadas pela Secretaria Nacional de Habitação (SNH) do MCIDADES, para orientar o poder público e demais atores envolvidos a uma abordagem adequada da questão fundiária nos PLHIS, especificamente no que se refere à produção habitacional. Sob a ótica da $\mathrm{SNH}$, três aspectos devem ser considerados para a abordagem da questão (MINISTÉRIO..., 2009):

(a) o volume de terra necessário ao atendimento das demandas habitacionais acumuladas e futuras;

(b) o volume de recursos necessário a esse atendimento; e

(c) o potencial de terras existente e disponível no município para a construção de novas moradias.

A análise buscou identificar como esses aspectos foram tratados nos referidos documentos e de que forma orientaram a definição das estratégias de ação propostas pelo PLHIS para viabilizar a terra necessária ao enfrentamento da problemática habitacional local. Para tanto, foram levantados no Plano de Habitação (PREFEITURA..., 2011) os seguintes elementos:

(a) as necessidades habitacionais locais: as estimativas e formas de caracterização do déficit habitacional e da demanda futura por novos domicílios;

(b) a problemática fundiária do município: as estimativas de terra, seus custos e sua existência e disponibilidade para a política de produção habitacional; e

(c) as estratégias de ação formuladas para a questão fundiária: os programas, metas, recursos e instrumentos de ação propostos para a viabilização da terra necessária à produção de moradias, considerando as necessidades habitacionais do município e o horizonte temporal do planejamento habitacional proposto pelo Plano.

Para problematização e complementação da análise dos elementos expostos, foram também verificadas as implicações das legislações urbanísticas locais na destinação e viabilização efetiva das propostas formuladas pelo PLHIS, considerando as disposições estabelecidas nos instrumentos municipais que dispõem sobre a política urbana, a saber, o Plano Diretor e as leis a ele complementares (CAMPINAS, 2006, 2012, 2014). 
Cabe destacar que a pesquisa teve caráter descritivo, analítico e interpretativo, configurandose na linha de uma pesquisa qualitativa. Teve-se como foco identificar a abordagem da questão fundiária na política habitacional institucionalizada nos documentos oficiais do PLHIS e das legislações urbanísticas locais, não fazendo parte do trabalho o contato com as gestões públicas ou Conselho Municipal de Habitação, para esclarecimentos ou verificação da veracidade das informações apresentadas nesses documentos.

\section{Demandas habitacionais e fundiárias em campinas}

O município de Campinas figura entre as principais aglomerações e capitais ricas brasileiras, e desempenha grande importância econômica e funcional na Região Metropolitana a qual integra (MINISTÉRIO..., 2008c). Em suas especificidades, apresenta inúmeras desigualdades e problemas urbanísticos e sociais: dispersão de bairros sem a correspondente implantação de infraestrutura e de serviços públicos; descontinuidade dos tecidos urbanos; manutenção de grandes parcelas territoriais desocupadas; segregação socioespacial; e adensamento da população de baixa renda em conjuntos habitacionais e em regiões precárias específicas e periféricas (PIRES, 2007).

Em termos de problemática habitacional, em 2010, 53.365 domicílios urbanos $(15,5 \%$ do total do município) encontravam-se na informalidade. Pelas estimativas apresentadas em seu PLHIS a partir de levantamento próprio, essa informalidade estava representada por 234 assentamentos precários, constituídos por favelas e loteamentos irregulares ou clandestinos, o que compreendia pouco mais de 180 mil pessoas, $16,6 \%$ da população total da cidade (PREFEITURA..., 2011).

Em números, os assentamentos de favelas superam os loteamentos irregulares e clandestinos, constituindo 194 núcleos, com um total de 29.078 domicílios ocupando espaços livres de loteamentos, muitos dos quais irregulares, várzeas de rios e córregos, encostas íngremes, bem como áreas não edificáveis à margem de rodovias e ferrovias. Os loteamentos, em grande parte periféricos, constituem 40 núcleos, com um total de 24.287 domicílios, e compreendem a ocupação irregular ou clandestina de antigos empreendimentos habitacionais promovidos pelo setor público e privado (PREFEITURA..., 2011).

Segundo o PLHIS, a maior parte do quadro de informalidade concentra-se nas regiões sul, oeste e sudoeste do município (Figura 1). Essas regiões, entremeadas por vazios urbanos ou glebas com características rurais, conformam um território disperso e fragmentado, marcado por processos irregulares de diferentes usos e ocupações. Nas últimas décadas, esse território assistiu, de um lado, o crescimento de suas periferias, com a reprodução da informalidade, e, de outro lado, sua reconfiguração com a formação de novos usos e centralidades, estimulada pela implantação de loteamentos fechados para alta renda e por empreendimentos estratégicos ao desenvolvimento econômico do município (FREITAS, 2008).

Para estimar as necessidades fundiárias e os custos da política de habitação, visando à verificação do potencial de terras existentes e à formulação de estratégias para enfrentamento do quadro habitacional evidenciado, os 234 assentamentos precários foram divididos pelo Plano de Habitação em três categorias, para as quais foram identificados eixos centrais de atuação e intervenção, adotando-se metodologia sugerida por Denaldi (2009). Tais categorias dizem respeito à perspectiva de consolidação e integração dos núcleos à cidade formal, e compreendem assentamentos consolidados, consolidáveis e não consolidáveis.

Os núcleos consolidados correspondem aos assentamentos já integrados urbanisticamente à cidade, que não demandam intervenções físicas de urbanização ou reordenamento urbano e que compreendem o eixo de regularização fundiária e a melhoria da unidade habitacional da política. Já os núcleos consolidáveis demandam algum tipo de operação física de urbanização ou de reordenamento urbano, apresentando condições favoráveis de integração e intervenção urbanística e ambiental, que podem ou não demandar ações de remoção de unidades habitacionais (DENALDI, 2009). Esses núcleos constituem o eixo de atuação da política de urbanização de assentamentos, porém se enquadram parcialmente no eixo de atuação da política de produção de unidades habitacionais, uma vez que as ações de remoção exigem a construção de novas moradias, seja na própria área do assentamento (remanejamento), seja em novos espaços de terra (reassentamento). 
Figura 1- Assentamentos precários em Campinas

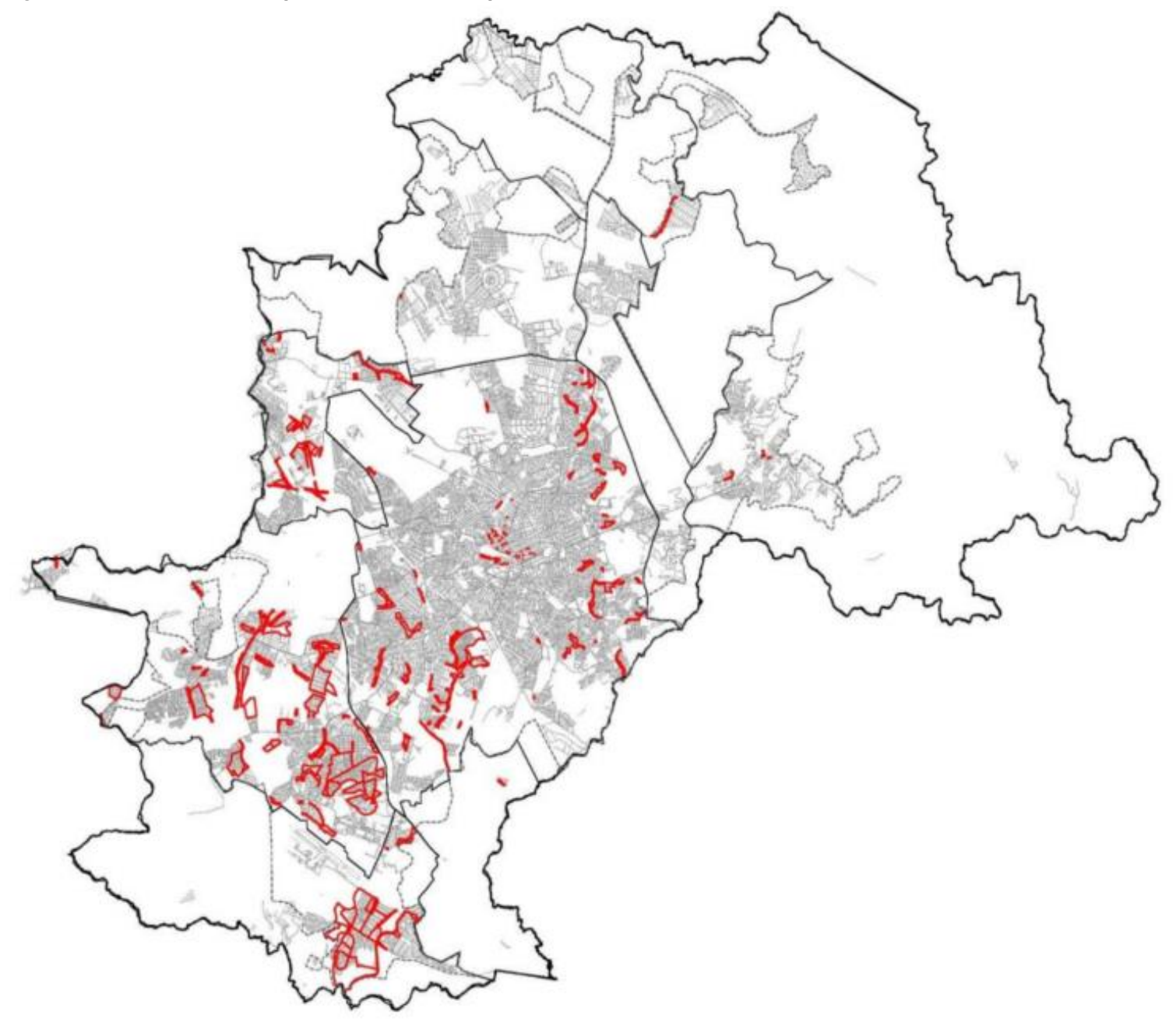

Fonte: Prefeitura Municipal de Campinas (2011, p. 296).

Por sua vez, os núcleos não consolidáveis constituem assentamentos que não apresentam condições de recuperação urbanística, ambiental ou de reordenamento urbano e, por tal aspecto, demandam remoção total das unidades habitacionais, com reassentamento em novas terras (DENALDI, 2009). Essa última categoria representa por completo o eixo de produção de unidades habitacionais do Plano de Habitação de Campinas, o qual deverá ser viabilizado por meio de uma política efetiva de apropriação de terras pautada no cumprimento da função social da propriedade (PREFEITURA..., 2011).

O enquadramento dos núcleos nas três categorias permitiu ao PLHIS apontar o cenário do déficit habitacional em assentamentos precários em Campinas, em 2010. No Plano, as necessidades de remanejamento e reassentamento de moradias representam o componente quantitativo do déficit, e as demandas de urbanização e regularização fundiária constituem o déficit por inadequação habitacional, ou déficit qualitativo.

Ao todo, o PLHIS identificou 4.721 domicílios informais consolidados que demandam ações de regularização fundiária, o que representa $9 \%$ dos domicílios totais levantados em assentamentos precários (PREFEITURA..., 2011). Os assentamentos consolidáveis abrangem a demanda de 31.245 domicílios - 58,54\% do total da precariedade -, dos quais 30.816 apresentam necessidade de urbanização $(57,74 \%)$ e $429(0,8 \%)$ devem ser objeto de remanejamento de unidades habitacionais (PREFEITURA..., 2011). A inadequação habitacional abrange $66,74 \%$ do déficit em assentamentos (PREFEITURA..., 2011). Já outros 17.399 domicílios, 32,6\% do total de domicílios precários, considerados não consolidáveis pelo PLHIS, constituem parte do déficit quantitativo; somados à demanda de remanejamento, tais domicílios abrangem 33,40\% 
do déficit em assentamentos precários (PREFEITURA..., 2011).

O Plano levantou ainda como componente do déficit quantitativo a demanda habitacional não inserida em assentamentos precários (13.043 domicílios), para a qual também seria necessária a produção de moradias em novas terras (PREFEITURA..., 2011). Tal procedimento foi efetuado no PLHIS por meio da atualização do déficit habitacional de 2000, estimado pela Fundação João Pinheiro (FUNDAÇÃO..., 2005), subtraindo-se a demanda levantada nos assentamentos precários.

Ressalta-se que, para a PNH, a demanda futura por HIS também repercute na composição do quadro da problemática habitacional. Assim como o déficit, tal demanda exigirá espaços de terra e a formulação de propostas e programas de ação para seu enfrentamento. Os PLHIS devem encará-la sob uma perspectiva estratégica que vise coibir que suas soluções de acesso a terra e a moradia sejam soluções precárias, que reforcem e realimentem o circuito de consolidação e continuidade da precariedade habitacional (MINISTÉRIO..., 2009).

Nessa perspectiva, pelo fato de o PLHIS abarcar como seu horizonte temporal o período 2011-2023, foi ainda considerada a previsão da demanda por novos domicílios, a se estabelecer neste período em Campinas, dentro da faixa de renda considerada prioritária pelo Plano - até cinco salários mínimos (PREFEITURA..., 2011). A previsão tomou como referência o cálculo da demanda futura por moradias feito pelo Centro de Desenvolvimento e Planejamento Regional (CENTRO..., 2009) para todos os municípios brasileiros.

A Tabela 1, a seguir, apresenta a síntese das necessidades habitacionais retratadas em Campinas em seu Plano de Habitação.

Para a quantificação da demanda de terra, o PLHIS adotou como método o estabelecimento de uma fração ideal de terreno para cada domicílio a ser atendido pela produção habitacional, tendo em vista a possibilidade de adoção de diferentes tipologias habitacionais. Utilizou-se como referência a cota bruta de $250 \mathrm{~m}^{2}$ por unidade habitacional, obtendo-se a necessidade de $15.989 .250 \mathrm{~m}^{2}$ de terra para as ações de produção de moradias (PREFEITURA..., 2011).

Atendendo-se às sugestões expressas pela $\mathrm{SNH}$ para abordagem adequada do tema da terra no PLHIS (MINISTÉRIO..., 2009) e partindo-se da hipótese da inexistência de uma política de solo efetiva para a obtenção de terra, os custos de atendimento das necessidades habitacionais girariam em torno de mais de três bilhões de reais (Tabela 2). Esses custos foram estimados pelo Plano de Habitação de Campinas, tendo sido adotados como referência os valores praticados pelo Programa Minha Casa, Minha Vida (PMCMV), que considera entre os parâmetros de custo da unidade habitacional os custos da edificação, da infraestrutura, dos equipamentos comunitários, dos benefícios e despesas indiretas da construção e, dentre outros, do terreno (CAIXA..., 2009). Embora o PMCMV identifique esses elementos como componentes do custo da moradia, seus valores individuais, sobretudo do terreno, não são identificados. O Programa identifica apenas os custos totais da unidade habitacional, os quais, nas regiões metropolitanas paulistas, atingem R \$ 50.000,00 (CAIXA..., 2009).

Para a quantificação da demanda de terra, o PLHIS adotou como método o estabelecimento de uma fração ideal de terreno para cada domicílio a ser atendido pela produção habitacional, tendo em vista a possibilidade de adoção de diferentes tipologias habitacionais. Utilizou-se como referência a cota bruta de $250 \mathrm{~m}^{2}$ por unidade habitacional, obtendo-se a necessidade de 15.989.250 $\mathrm{m}^{2}$ de terra para as ações de produção de moradias (PREFEITURA..., 2011).

Tabela 1 - Necessidades habitacionais em Campinas, 2011-2023

\begin{tabular}{lll}
\hline \multicolumn{1}{c}{ Componente } & \multicolumn{1}{c}{ Domicílios } & Total \\
\hline \multirow{3}{*}{$\begin{array}{l}\text { Déficit Habitacional } \\
\text { (Quantitativo) 2010 }\end{array}$} & Em assentamentos precários (levantamento próprio) & 17.828 \\
\cline { 2 - 3 } & Fora de assentamentos precários (Fundação João & 13.043 \\
& Pinheiro) & 30.871 \\
\cline { 2 - 3 } $\begin{array}{l}\text { Inadequação Habitacional } \\
\text { (Qualitativo) 2010 }\end{array}$ & Total Déficit Habitacional (Quantitativo) & 35.537 \\
\hline \multirow{2}{*}{$\begin{array}{l}\text { Demanda Futura por HIS (2011- } \\
\text { 2023) }\end{array}$} & Total inadequação habitacional (Qualitativo) & 35.537 \\
\cline { 2 - 3 } & 3 a 3 s.m. 5 s.m. & 22.171 \\
\cline { 2 - 3 } & Total 0 a 5 s.m.(CEDEPLAR/UFMG/MCIDADES) & 33.515 \\
\hline
\end{tabular}

Fonte: Prefeitura Municipal de Campinas (2011, p. 359). 
Tabela 2 - Estimativa de terra e custos para atendimento da demanda por novas moradias em Campinas, 2011-2023

\begin{tabular}{|c|c|c|c|c|}
\hline Componente & \multicolumn{2}{|c|}{ Domicílios } & $\begin{array}{c}\text { Área Total Estimada } \\
\left(\mathrm{m}^{2}\right)^{*}\end{array}$ & $\begin{array}{c}\text { Custo de } \\
\text { Atendimento }(\mathbf{R} \$)^{* *}\end{array}$ \\
\hline \multirow{3}{*}{$\begin{array}{l}\text { Déficit em } \\
\text { assentamentos } \\
\text { precários } 2011\end{array}$} & Remanejamento & $\overline{429}$ & $107.250,00$ & $21.450 .000,00$ \\
\hline & Reassentamento & 17.399 & $4.349 .750,00$ & $869.950 .000,00$ \\
\hline & Total & 17.828 & $4.457 .000,00$ & $891.400 .000,00$ \\
\hline $\begin{array}{l}\text { Déficit fora de } \\
\text { assentamentos } \\
\text { precários } 2011\end{array}$ & & 13.043 & $3.260 .750,00$ & $652.150 .000,00$ \\
\hline \multirow{2}{*}{$\begin{array}{l}\text { Déficit quantitativo } \\
\text { Total } 2011\end{array}$} & $\begin{array}{l}\text { Sem } \\
\text { remanejamento }\end{array}$ & 30.442 & $7.610 .500,00$ & $1.522 .100 .000,00$ \\
\hline & $\begin{array}{l}\text { Com } \\
\text { remanejamento }\end{array}$ & 30.871 & $7.717 .750,00$ & $1.543 .550 .000,00$ \\
\hline $\begin{array}{l}\text { Demanda } \\
\text { Habitacional Futura } \\
\text { Prioritária } 2011-2023 \\
(0 \text { a } 5 \text { s.m.) }\end{array}$ & & 33.515 & $8.378 .750,00$ & $1.675 .750 .000,00$ \\
\hline \multirow{2}{*}{$\begin{array}{l}\text { Política de Produção } \\
\text { Habitacional e } \\
\text { Fundiária 2011-2023 }\end{array}$} & $\begin{array}{l}\text { Sem } \\
\text { remanejamento }\end{array}$ & 63.957 & $15.989 .250,00$ & $3.197 .850 .000,00$ \\
\hline & $\begin{array}{l}\text { Com } \\
\text { remanejamento }\end{array}$ & 64.386 & $16.096 .500,00$ & $3.219 .300 .000,00$ \\
\hline
\end{tabular}

Nota: ${ }^{*}$ Cota bruta de terreno: $250 \mathrm{~m}^{2} /$ unidade habitacional; $\mathrm{e}{ }^{* *} \mathrm{R} \$$ médio/unidade habitacional: 50.000,00 (PMCMV). Fonte: adaptado de Prefeitura Municipal de Campinas (2011).

Atendendo-se às sugestões expressas pela $\mathrm{SNH}$ para abordagem adequada do tema da terra no PLHIS (MINISTÉRIO..., 2009) e partindo-se da hipótese da inexistência de uma política de solo efetiva para a obtenção de terra, os custos de atendimento das necessidades habitacionais girariam em torno de mais de três bilhões de reais (Tabela 2). Esses custos foram estimados pelo Plano de Habitação de Campinas, tendo sido adotados como referência os valores praticados pelo Programa Minha Casa, Minha Vida (PMCMV), que considera entre os parâmetros de custo da unidade habitacional os custos da edificação, da infraestrutura, dos equipamentos comunitários, dos benefícios e despesas indiretas da construção e, dentre outros, do terreno (CAIXA..., 2009). Embora o PMCMV identifique esses elementos como componentes do custo da moradia, seus valores individuais, sobretudo do terreno, não são identificados. O Programa identifica apenas os custos totais da unidade habitacional, os quais, nas regiões metropolitanas paulistas, atingem R \$ 50.000,00 (CAIXA..., 2009).

Cabe registrar que, mesmo que o PMCMV incluísse o custo do terreno nos valores por ele praticados, sua normatização estabelece entre os critérios de atendimento a priorização dos municípios que doarem terrenos para a implantação de empreendimentos ou que implementarem os instrumentos do Estatuto da Cidade voltados ao controle da retenção especulativa de áreas vazias ociosas (BRASIL 2009; CAIXA..., 2009). Levando-se em conta o peso da participação do Programa nas ações da política habitacional brasileira (FERREIRA, 2012), esse critério reforça a necessidade dos poderes públicos locais, no processo de formulação de seus PLHIS, de empreender esforços para quantificar a terra e definir estratégias que busquem destiná-las para HIS, considerando os pressupostos da $\mathrm{PNH}$.

\section{Tema da terra no plano de habitação de campinas e sua articulação com o Plano Diretor}

Conforme orientações da SNH, além de identificar as necessidades fundiárias e os recursos para enfrentamento da problemática habitacional local, para uma abordagem do tema da terra, os PLHIS devem verificar, quantificar e caracterizar o potencial de terras existente e disponível para HIS, visando a sua posterior destinação para a política de produção habitacional (MINISTÉRO..., 2008a, 2009).

No caso de Campinas, a abordagem do potencial de terras no PLHIS incluiu as reservas de áreas livres de propriedade pública e os terrenos vazios de propriedade privada não utilizados ou 
subutilizados. Em relação às áreas públicas, o PLHIS informou a existência de $45.825,70 \mathrm{~m}^{2}$ de terra pertencente à Fazenda Estadual e mais $47.083,20 \mathrm{~m}^{2}$ de terra de propriedade do Governo do Estado de São Paulo, montante apenas informado, não mapeado e não inserido na pauta de disponibilização para HIS. Foram ainda mapeados cerca de 200 mil metros quadrados de terra de propriedade da Companhia de Habitação Popular de Campinas (COHAB) e do Fundo de Apoio à População de Sub-Habitação Urbana de Campinas (FUNDAP) ${ }^{2}$. Os terrenos que compõem esse montante também não foram considerados para fins da política habitacional pelo PLHIS. Muitos apresentam destinação comercial - embora livres de edificação; outros constituem terrenos de pequenas dimensões ou imóveis comunitários vagos, distribuídos isoladamente em empreendimentos habitacionais construídos pela própria Companhia (PREFEITURA..., 2011). Segundo o PLHIS, em função de sua vacância, esses terrenos e imóveis estavam sendo apropriados para sanar o déficit orçamentário da empresa: somente em 2010, a COHAB colocou à venda $33.420,28 \mathrm{~m}^{2}$ de terrenos vazios em Campinas, $4.781,82 \mathrm{~m}^{2}$ de imóveis comunitários ociosos e mais $5.712,08 \mathrm{~m}^{2}$ de terrenos inutilizados situados fora do município, decorrentes de atuações realizadas em seu passado (PREFEITURA..., 2011).

Em relação às terras de propriedade privada, o PLHIS apresentou um levantamento de mais de 84 milhões de metros quadrados de terrenos e glebas vazias no interior do perímetro urbano, o equivalente a $21,6 \%$ da área urbana total do município (PREFEITURA..., 2011). Embora não apresente informações conclusivas, o Plano afirma que grande parte desses espaços possui dívidas tributárias com a Prefeitura, as quais, em muitos casos, equivalem ou superam o valor venal dos imóveis (PREFEITURA..., 2011).

Ressalta-se que as necessidades fundiárias para atendimento das demandas presentes e futuras por HIS em Campinas, segundo o PLHIS, abrangem pouco mais de 15 milhões de metros quadrados, o que significa que o potencial de terras levantado pelo Plano, em termos quantitativos, se mostra mais do que suficiente para a base da política habitacional. Cabe considerar, no entanto, que o levantamento desse potencial baseou-se na verificação preliminar de sua configuração

${ }^{2} \mathrm{~A}$ COHAB-Campinas é uma empresa de economia mista responsável pela execução dos programas e ações da política municipal de habitação. O Fundap é um fundo municipal gerido por um conselho participativo, que agrega recursos e imóveis provenientes da cobrança de contrapartidas decorrentes, sobretudo, da implantação de empreendimentos habitacionais de interesse social no município (PREFEITURA..., 2011). territorial, demonstrando apenas um cenário geral da existência de terras. Segundo diretrizes do próprio PLHIS, seria necessário um levantamento mais aprofundado do conjunto das áreas mapeadas, bem como uma análise real de sua viabilidade técnico-financeira e de sua inserção urbanística para efetivá-lo como base das ações de produção habitacional, uma vez que as terras públicas foram descartadas pelo município (PREFEITURA..., 2011).

Considerando o marco legal urbanístico de Campinas, destaca-se que o Plano Diretor (CAMPINAS..., 2006) transfere ao Plano de Habitação o levantamento completo dos vazios urbanos para a constituição de um banco de terras aptas para HIS. Admite para isso a possibilidade de regulamentação dos instrumentos de política fundiária para intervenção na propriedade do imóvel, dispostos no Estatuto da Cidade e apenas previstos no Plano Diretor. A aplicação de instrumentos que ampliem o acesso à terra urbanizada e que combatam a retenção especulativa de terras - tais como as Zonas Especiais de Interesse Social (ZEIS), associadas ao Parcelamento, Edificação e Utilização Compulsórios (PEUC), ao IPTU progressivo no tempo, à desapropriação com pagamento em títulos da dívida pública e ao direito de preempção -, assim como a aplicação de instrumentos já existentes em Campinas (e.g. dação em pagamento) poderiam ser viabilizadas por meio da regulamentação do PLHIS por lei ou dos planos locais de gestão (PLGs) referenciados no Plano Diretor (CAMPINAS, 2006).

Os PLGs constituem instrumentos jurídicourbanísticos específicos das macrozonas de desenvolvimento urbano definidas pelo Plano Diretor de Campinas. Têm por objetivo estabelecer diretrizes de intervenção, o detalhamento de políticas setoriais, bem como a adequação de parâmetros de parcelamento, uso e ocupação do solo aos condicionantes ambientais, urbanísticos e socioeconômicos de cada macrozona (CAMPINAS, 2006).

Seguindo-se as diretrizes estabelecidas no Plano Diretor, tanto o PLHIS como os PLGs propuseram a localização de ZEIS para produção de HIS em Campinas. As terras delimitadas apresentam grande diversidade quanto ao quesito localização: o PLHIS buscou localizações mais centrais, mais bem inseridas no território urbano e relacionadas às demandas habitacionais específicas de cada macrozona, enquanto os PLG(s) concentraram a delimitação de terras em áreas periféricas (Figura 3). 
Figura 3 - Localização das terras para HIS em Campinas

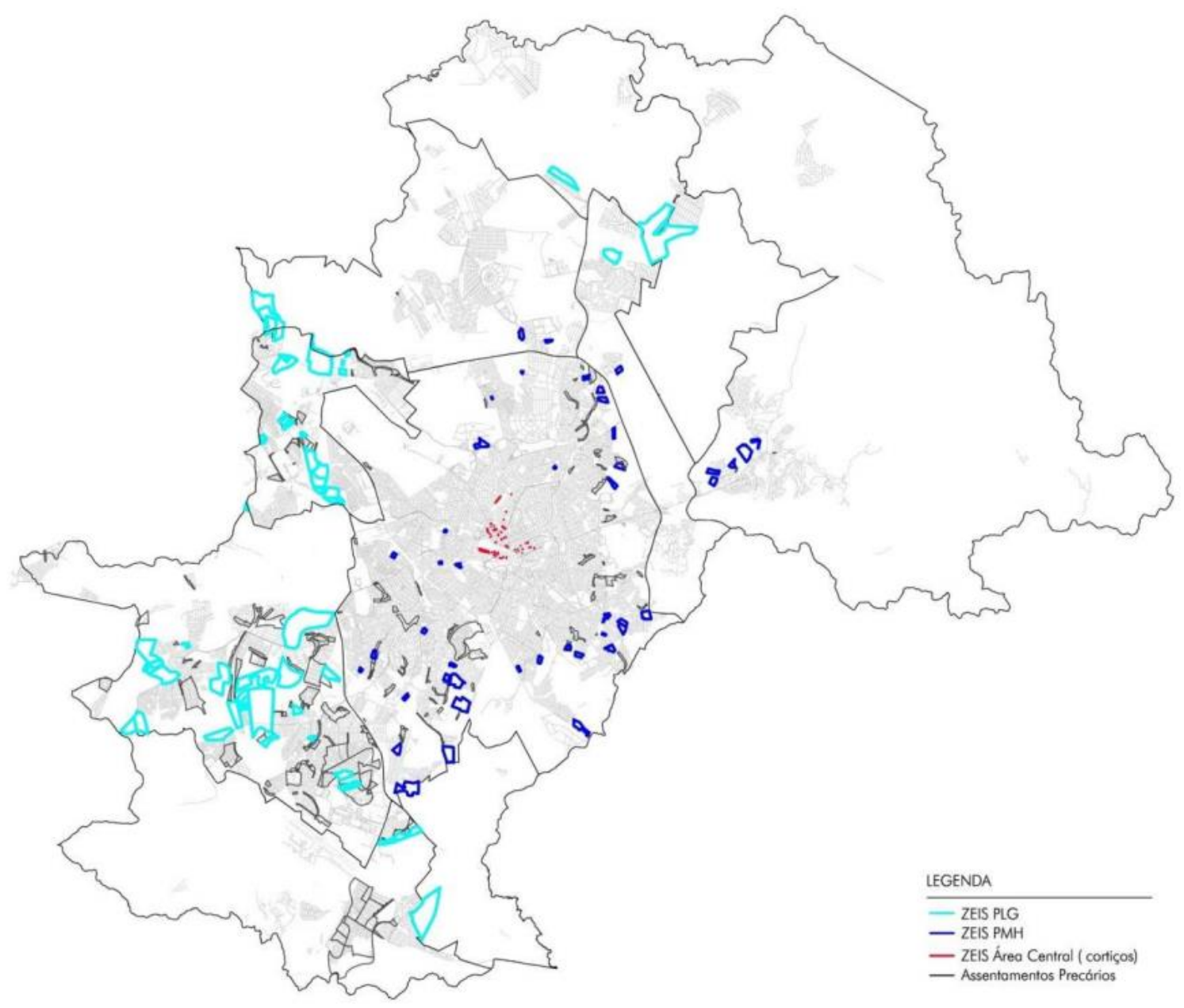

Fonte: Prefeitura Municipal de Campinas (2011, p. 369).

As áreas mapeadas pelo PLHIS podem ser consideradas como uma proposta para delimitação de novas ZEIS; já as terras delimitadas como ZEIS pelos PLGs podem ter maior efeito, uma vez que alguns dos PLGs foram aprovados ou estão em processo de aprovação pelo município de Campinas. Faz-se oportuno registrar que os PLGs, em suas leis e projetos de lei, intencionavam incorporar cerca de 20 milhões de metros quadrados de terra rural ao perímetro urbano de Campinas para abrigar novos projetos imobiliários, mesmo com $21,6 \%$ do território urbano vazio, inutilizado ou subutilizado (PREFEITURA..., 2011).

O PLHIS de Campinas incluiu inúmeras críticas em relação às ZEIS dos PLGs. As críticas se dão pelo fato de estas ZEIS estarem concentradas nas grandes regiões, que não apenas absorvem um significativo contingente dos problemas sociais associados à precariedade habitacional e à carência de equipamentos urbanos e oportunidades de emprego e renda, mas também apresentam os índices de maior vulnerabilidade social da RMC (PREFEITURA..., 2011).

A orientação do PLHIS de Campinas foi para que os vazios urbanos existentes nas regiões com concentração de ZEIS pudessem servir para a implantação de maiores urbanidades, contrariando as propostas dos PLGs de destiná-los para a implantação de mais empreendimentos habitacionais voltados à população de baixa renda (PREFEITURA..., 2011). Para o PLHIS, a concentração de ZEIS nessas regiões de grande precariedade e vulnerabilidade de Campinas tenderia a reforçar a desigualdade socioespacial presente no município, ao passo que deixariam intocados os inúmeros vazios urbanos existentes em áreas de urbanização já consolidada (PREFEITURA..., 2011).

A localização periférica das ZEIS dos PLGs tende a reforçar uma lógica de investimentos públicos em HIS que se expressa também na escala da

226 Ribeiro, J. A. Z. M. T.; Moreira, T. A. 
Região Metropolitana de Campinas (RMC). Segundo Silva (2012), muitas das ZEIS instituídas na RMC e em Campinas, assim como grande parte dos recursos públicos investidos em habitação entre os anos de 2008 e 2011, foram efetivadas em áreas periféricas ou ainda não incorporadas ao processo de urbanização, localizadas nas fronteiras dos municípios.

As críticas do PLHIS às ZEIS dos PLGs apontaram para a necessidade de alterações estruturais de suas localizações. Contudo, pelo fato de o PLHIS constituir um documento municipal administrativo que não possui teor de lei, os novos espaços de terras para HIS por ele propostos não foram levados a cabo, tornando as ZEIS dos PLGs/Plano Diretor a base fundiária prioritária das ações da política habitacional local. Considerando suas delimitações, essas ZEIS totalizam 17.002.171,66 $\mathrm{m}^{2}$ (CAMPINAS, 2006, 2012, 2014), montante suficiente para o enfrentamento das necessidades habitacionais levantadas pelo Plano de Habitação de Campinas.

\section{Estratégias de ação para viabilização da terra}

É importante considerar que o PLHIS constitui apenas um dos instrumentos da política urbanohabitacional e dificilmente consegue abranger todos os aspectos e meios necessários para efetivar sua articulação a uma política de solo (DENALDI; BRUNO FILHO, 2013). A forma como a viabilização da terra é considerada nas linhas e estratégias de ação do PLHIS não exprime, necessariamente, possibilidades práticas de intervenção no quadro das necessidades fundiárias e habitacionais. Por outro lado, o fato de ser apenas um dos instrumentos não significa que seu discurso não possa revelar a gênese das ações e o grau das intenções a respeito da viabilização da terra para moradia.

No caso de Campinas, as terras propostas para atendimento da demanda habitacional priorizada pelo PLHIS se configuram como terras de propriedade privada, uma vez que não foram incluídas como propostas de destinação para HIS as terras de propriedade pública. Considerando o exposto, as estratégias de ação formuladas pelo PLHIS caminham em dois sentidos:

(a) a compra direta de terra ou sua negociação com proprietários de terra; e

(b) a aplicação de uma política fundiária entendida como uma política que visa intervir sobre o uso da propriedade privada, visando ao cumprimento de sua função social para fins de moradia.
Considerando as Estratégias de Ação do PLHIS (PREFEITURA..., 2011), as táticas voltadas para a compra e desapropriação de terras se enquadram nas linhas de ação propostas para a produção de HIS pelo Plano de Habitação, uma vez que para essas linhas foram indicados recursos orçamentários para suprir os custos inicialmente estimados para atendimento das necessidades habitacionais, entre os quais se incluíam os custos do terreno.

Conforme tratado anteriormente, os custos estimados pelo PLHIS para esse atendimento atingiam R\$ 3.219.300.000,00. Considerando a estimativa, como meta para a produção pública de moradias, o PLHIS indica uma previsão orçamentária de recursos da ordem de $\mathrm{R} \$$ 3.344.450.000,00. Deste total, 73,8\% seriam capitalizados no âmbito dos programas habitacionais desenvolvidos pelo governo federal em especial o PMCMV; $18,1 \%$ ficariam a cargo do governo estadual; e apenas $8,1 \%$ seriam investimentos próprios do município (PREFEITURA..., 2011). O PLHIS não informa se a quantidade de recursos indicados como previsão de aplicação para o município está relacionada à capacidade de endividamento do poder público local.

Já a estratégia de aplicação de uma política fundiária se enquadra nas metas de ação voltadas ao desenvolvimento normativo e institucional do município, cujas propostas se pautam na revisão das legislações urbanísticas locais, objetivando sua reformulação e a regulamentação dos instrumentos do Estatuto da Cidade previstos no Plano Diretor (PREFEITURA..., 2011).

As recomendações do PLHIS para o desenvolvimento normativo e institucional classificam-se como metas prioritárias que seriam atendidas no período 2011-2013 de implementação do Plano, com exceção ao início de aplicação dos instrumentos do Estatuto da Cidade, previsto para o período 2014-2017. Até o início dessa aplicação, excluindo-se os empreendimentos habitacionais do PMCMV já aprovados pelo poder público local, o PLHIS estimou uma espécie de congelamento da política de produção habitacional para atendimento massivo do déficit por inadequação, o qual representava $66,74 \%$ da precariedade habitacional presente em 2011 em Campinas (PREFEITURA..., 2011).

Fica clara a recomendação do PLHIS para que o município viabilize a terra privada para HIS mediante uma política fundiária, dando preferência às terras por ele propostas e não as ZEIS demarcadas pelos PLGs/Plano Diretor. Essa política dependeria, no entanto, de processos cuja 
solução não se revela de forma tão simples como se coloca nas metas de ação normativa e institucional do PLHIS. A intervenção sobre a propriedade da terra por meio da aplicação articulada dos instrumentos do Estatuto da Cidade antecede a obtenção efetiva da terra para a base da política habitacional. Mesmo que o PLHIS preveja a regulamentação dos instrumentos para os primeiros anos da política, é importante considerar que, conforme suas próprias orientações, essa regulamentação parte da ideia de um processo participativo de revisão da legislação. Para Ferreira (2005), processos participativos geralmente são marcados por conflitos que envolvem a definição da apropriação do território, o que faz com que a construção de um pacto social para o desenvolvimento e a redistribuição equitativa do solo urbanoexijaum tempo muito maior do que o naturalmente empreendido na elaboração isolada e unilateral das legislações urbanísticas.

Vale ainda observar que, segundo Rolnik (2010), uma vez regulamentados, os instrumentos urbanísticos previstos no Estatuto da Cidade apresentam um tempo próprio de aplicação, que deve ser considerado em termos de planejamento e efetividade das ações no horizonte da política urbana. Considerando essa observação, vale destacar que os tempos estimados no PLHIS para a implementação de uma política de terras pode ser relativamente curto, ponderando: (a) a necessidade e o tempo de elaboração ou revisão das legislações urbanísticas vigentes em Campinas;

(b) o tempo até se chegar à aplicação efetiva dos instrumentos; e

(c) o tempo efetivo e particular de cada instrumento.

Então, como fica a atual necessidade da demanda por novas moradias? Considerando as variáveis temporais e a força com que se desenvolve a produção habitacional por meio do PMCMV (FERREIRA, 2012), assim como o fato de o PLHIS considerar como estratégia de ação a negociação e compra com proprietários de terra e agentes promotores imobiliários (Quadro 1), a constituição da base da política habitacional por meio de uma política fundiária poderá caminhar em paralelo ou na perpendicular das ações planejadas pelo próprio PLHIS para o desenvolvimento institucional do Município.

\section{Considerações finais}

Considerando o consenso teórico de que a terra urbana é componente essencial das políticas sociais de habitação, este artigo teve por objetivo analisar como sua viabilização para a produção de moradias foi colocada no desenho da política institucionalizada no Plano de Habitação do município de Campinas/SP, formulado no contexto de implementação da nova Política Nacional de Habitação (PNH).

\section{Quadro 1 - Estratégias para viabilização da terra, segundo programas de ação propostos no Plano de} Habitação de Campinas

\begin{tabular}{|c|c|c|}
\hline Linhas de ação & Estratégias & \\
\hline \multirow{2}{*}{$\begin{array}{l}\text { Produção pública } \\
\text { de unidades } \\
\text { habitacionais }\end{array}$} & Compra de terra & $\mathrm{x}$ \\
\hline & $\begin{array}{l}\text { Negociação direta com proprietários de terra, promotores } \\
\text { imobiliários e mercado imobiliário }\end{array}$ & $\mathrm{x}$ \\
\hline \multirow{7}{*}{$\begin{array}{l}\text { Desenvolvimento } \\
\text { Normativo e } \\
\text { Institucional }\end{array}$} & $\begin{array}{l}\text { Cobrança de um percentual de recursos de novos empreendimentos } \\
\text { para aplicação no fundo de habitação }\end{array}$ & $\mathrm{x}$ \\
\hline & Zonas Especiais de Interesse Social (ZEIS) & $\mathrm{x}$ \\
\hline & Parcelamento, edificação e utilização compulsórios (PEUC) & $\mathrm{x}$ \\
\hline & IPTU progressivo no tempo & $\mathrm{x}$ \\
\hline & Desapropriação com pagamento em títulos da dívida pública & $\mathrm{x}$ \\
\hline & Dação em pagamento & $\mathrm{x}$ \\
\hline & $\begin{array}{l}\text { Revisão, regulamentação ou elaboração de legislações urbanísticas } \\
\text { para efetivação dos instrumentos propostos como meta do Programa }\end{array}$ & $\mathrm{x}$ \\
\hline
\end{tabular}

Fonte: adaptado de Prefeitura Municipal de Campinas (2011). 
Sob diretrizes da PNH, além de identificar as necessidades de terra e os recursos para enfrentamento das problemáticas habitacionais presentes e futuras, o Plano de Habitação deve verificar, quantificar e caracterizar o potencial fundiário existente e disponível para HIS, visando a sua posterior destinação para a política de produção habitacional. Tomando-se como caso o município de Campinas, observou-se que, embora a questão fundiária tenha sido tratada considerando as diretrizes colocadas, a abordagem não orienta a definição de estratégias de ação efetivas no enfrentamento dos problemas habitacionais a partir dos pressupostos da nova $\mathrm{PNH}$, os quais se fundamentam nos princípios e diretrizes da política urbana referenciados na Constituição e no Estatuto da Cidade.

A viabilização de terras para moradia se insere no Plano de Habitação, tanto na linha programática de desenvolvimento normativo e institucional, quanto na linha de produção habitacional. Para esta, a estratégia de ação se pauta na compra ou na negociação da terra com proprietários e agentes promotores imobiliários - estratégiarecorrente nas práticas empreendidas no passado da política habitacional e tão cara às cidades brasileiras -, cujos recursos previstos se concentram majoritariamente nas possibilidades de sua captação nas esferas estadual e federal, isentando o município de maiores responsabilidades no financiamento da terra para a produção habitacional.

Para o desenvolvimento normativo e institucional, as estratégias para viabilização da terra estão pautadas na aplicação de uma política fundiária que visa intervir sobre a propriedade da terra, na busca por sua democratização, mas que se colocam como discurso, uma vez que tal política está condicionada a uma gestão urbana que se dedique à aplicação de instrumentos urbanísticos considerados fundamentais para essa intervenção.

Reconhece-se a limitação do plano de habitação como um instrumento que dificilmente se apropria de todos os meios necessários para a concretização de um planejamento habitacional que permita aplicar uma política fundiária para a democratização do acesso a terra. Essa democratização extrapola o âmbito do plano e remete a sua articulação com outros instrumentais da política urbana.

Em Campinas, essa articulação se dá, no entanto, com legislações urbanísticas corrompidas no tocante à aplicação de instrumentos urbanísticos e ao princípio da função social estabelecido no Estatuto da Cidade, o que corrobora para localizar territorialmente o atendimento das demandas por
HIS na periferia ou em regiões urbanas que já absorvem um significativo contingente dos problemas sociais associados à precariedade habitacional e à carência de equipamentos urbanos. Essa articulação dialoga com as áreas ainda não totalmente incorporadas ao processo de urbanização, mas consideradas prioritárias à ação habitacional por tais legislações, reforçando a tendência de segregação social não apenas na escala municipal, mas também na escala metropolitana.

O Plano de Habitação buscou questionar as bases das legislações urbanísticas vigentes em Campinas, sobretudo as Zonas Especiais de Interesse Social (ZEIS) destinadas à produção de moradias, mas as propostas voltadas à reversão de sua localização periférica e a delimitação de áreas mais adequadas para HIS não efetivam, em curto prazo, ações mais concretas. Tais propostas se delineiam como uma urgente necessidade de aplicação de uma política fundiária, observada no discurso do Plano como recomendação para a gestão pública.

As propostas para viabilizar a terra mediante políticas de solo estão, portanto, pautadas na crença de que o bom planejamento e a boa gestão do território possam reformular o quadro da problemática habitacional evidenciada no município. Isso se coloca como parte do desenvolvimento de um novo arranjo para as formas de gestão e controle do uso e ocupação do solo, o que traz implícita a necessidade de se iniciar uma nova cultura urbanística, para que a política fundiária saia do lócus que atualmente ocupa: entre a demanda de terra e o direito de propriedade.

\section{Referências}

BONDUKI, N. Do Projeto Moradia ao Programa Minha Casa, Minha Vida. Teoria e Debate, São Paulo, v. 82, p. 8-14, 2009. Disponível em: <http://www.fpabramo.org.br/uploads/TD82Nacional.pdf>. Acesso em: 9 maio 2013.

BONDUKI, N. O Modelo de Desenvolvimento Urbano de São Paulo Precisa Ser Revertido.

Estudos Avançados, São Paulo, v. 25, n. 71, p. 23-36, 2011.

BRASIL. Lei n ${ }^{\circ} 10.257$, de 10 de julho de 2001. Estabelece diretrizes gerais da política urbana. Diário Oficial da União, Brasília-DF, 10 jul. 2001. 
BRASIL. Lei ${ }^{\circ} 11.124$, de 16 de junho de 2005, que dispõe sobre o Sistema Nacional de Habitação de Interesse Social - SNHIS, cria o Fundo Nacional de Habitação de Interesse Social FNHIS e institui o Conselho Gestor do FNHIS. Diário Oficial da União, Brasília, 17 de junho de 2005.

CAIXA ECONÔMICA FEDERAL. Minha Casa, Minha Vida: moradia para as famílias, renda aos trabalhadores, desenvolvimento para o Brasil. Brasília: Caixa Econômica Federal, 2009.

CAMPINAS. Lei Complementar $\mathrm{n}^{\circ} 15$ de 27 de dezembro de 2006, que dispõe sobre o Plano Diretor do Município de Campinas. Diário Oficial do Município, Campinas, 29 de dezembro de 2006.

CAMPINAS. Lei Complementar $n^{\circ} 35$ de 20 de setembro de 2012, que dispõe sobre o Plano Local de Gestão da Macrozona 5 - MZ5 - Área de Requalificação Prioritária - ARP. Diário Oficial do Município, Campinas, 21 de setembro de 2012.

CAMPINAS. Lei Complementar $n^{\circ} 76$ de 17 de julho de 2014, que dispõe sobre o Plano Local de Gestão da Macrozona 9 - MZ9 - Área de Integração Noroeste - AIN do Município de Campinas. Diário Oficial do Município, Campinas, 21 de julho de 2014.

CARDOSO, P.; ROMEIRO, P. Sistema Nacional de Habitação de Interesse Social à Luz do Novo Marco Legal Urbanístico: subsídios para implementação nos estados e municípios - Lei Federal no 11.125/05. São Paulo: Instituto Pólis, 2008.

\section{CENTRO DE DESENVOLVIMENTO E} PLANEJAMENTO REGIONAL. Universidade Federal de Minas Gerais. Demanda Futura Por Moradia no Brasil 2003-2023: uma abordagem demográfica. Brasília: Ministério das Cidades, 2009.

DENALDI, R. Panorama da Política Habitacional no Brasil a Partir de Uma Leitura Regionalizada dos Recentes Planos Locais de Habitação de Interesse Social (PLHIS) Elaborados no País. In: ENCONTRO NACIONAL DA ANPUR, 15, Recife, 2013. Anais... Recife: ANPUR, 2013a.

DENALDI, R. Assentamentos Precários: identificação, caracterização e tipos de intervenção. In: MCIDADES, MINISTÉRIO DAS CIDADES. Curso à distância: planos locais de habitação de interesse social. Brasília: Ministério das Cidades, Secretaria Nacional de Habitação, 2009. p. 107-131.
DENALDI, R.(Org.). Planejamento

Hhabitacional: notas sobre a precariedade e terra nos Planos Locais de Habitação. São Paulo:

AnnaBlume, 2013b.

DENALDI, R.; BRUNO FILHO, F. G. Plano Diretor, Zonas Especiais de Interesse Social e a Articulação Com o Plano Local de Habitação. In: DENALDI, R. (Org.). Planejamento

Habitacional: notas sobre a precariedade e terra nos Planos Locais de Habitação. São Paulo: AnnaBlume, 2013.

DENALDI, R.; LEITÃO, K.; AKAISHI, A. O Recente Processo de Elaboração dos Planos Locais de Habitação de Interesse Social no Brasil: limitações e perspectivas. In: ENCONTRO NACIONAL DA ANPUR, 24., Rio de Janeiro, 2011. Anais... Rio de Janeiro: ANPUR, 2011.

FERREIRA, J. S. W.Alcances e Limitações dos Instrumentos Urbanísticos na Construção de Cidades Democráticas e Socialmente Justas. Brasília: Câmara Federal/CDUI; Ministério das Cidades, 2005.

FERREIRA, J. S. W. Produzir Casas ou Construir Cidades? Desafios para um novo Brasil urbano. São Paulo: LABHAB/FUPAM, 2012.

FUNDAÇÃO JOÃO PINHEIRO. Déficit

Habitacional no Brasil 2000. 2. ed. Belo Horizonte: Fundação João Pinheiro; Centro de Estatísticas e Informações, 2005.

FONSECA, M. de L.; FERNANDES, C. N.; TAVARES, H. C. Terra Para Habitação de Interesse Social na Região Metropolitana de São Paulo. In: DENALDI, R. (Org.). Planejamento Habitacional: notas sobre a precariedade e terra nos Planos Locais de Habitação. São Paulo: AnnaBlume, 2013.

FREITAS, E. L. H. Loteamentos Fechados. São Paulo, 2008. 203 f. Tese (Doutorado em Habitat) Faculdade de Arquitetura e Urbanismo, Universidade de São Paulo, São Paulo, 2008.

GOETZ, E. G. The Transformation of Public Housing Policy.Journal of the American Planning, Chicago, v. 78, n. 4, p. 452-463, 2012.

LADIS, J. D.; MCCLURE, K. Rethinking Federal Housing Policy.Journal of the American Planning, Chicago, v. 76, n. 3, p. 319-348, 2010.

MACEDO, J. Urban Land Policy and New Land Tenure Paradigms: legitimacy vs.legality in Brazilian cities. Land Use Policy, v. 25, n. 2, p. 259-270, 2008. 
MINISTÉRIO DAS CIDADES. Cadernos MCidades: Política Nacional de Habitação, Brasília, n. 4, 2006.

MINISTÉRIO DAS CIDADES. Guia de Adesão ao Sistema Nacional de Habitação de Interesse Social- SNHIS. Brasília: Ministério das Cidades; Secretaria Nacional de Habitação, 2008a.

\section{MINISTÉRIO DAS CIDADES. Manual Para}

Apresentação de Propostas: apoio à elaboração de Planos Habitacionais de Interesse Social. Brasília: Ministério das Cidades; Secretaria Nacional de Habitação; Fundo Nacional de Habitação de Interesse Social, 2008b.

MINISTÉRIO DAS CIDADES. Curso à

Distância: planos locais de habitação de interesse social. Brasília: Ministério das Cidades; Secretaria Nacional de Habitação, 2009.

MOREIRA, T. A. Falta o Falsa Política Habitacional y del Suelo. Ciudades, Puebla, México, v. 95, p. 39-46, 2012.

NASCIMENTO NETO, P.; MOREIRA, T. A.; SCHUSSEL, Z. das G. L. Housing Policy: acritical analysis on the Brazilian experience. TeMA Journal of Land Use, Mobility and Environment, Napoli, v. 5, n. 3, p. 65-76, 2012.

NEEDHAM, B.; VERHAGE, R. The Effect of Land Policy: quantity as well as quality is important. Urban Studies, v. 35, n. 1, p. 25 44,1998

OLIVEIRA, F. L. de; BIASOTTO, R. O acesso à Terra Urbanizada nos Planos Diretores brasileiros. In: SANTOS JUNIOR, O. A. dos; MONTANDON, D. T. (Orgs.). Os Planos Diretores Municipais Pós-Estatuto da Cidade: balanço crítico e perspectivas. Rio de Janeiro: Letra Capital; Observatório das Metrópoles IPPUR/URFJ, 2011.

PIRES, M. C. S. Morar na Metrópole: expansão urbana e mercado imobiliário na Região Metropolitana de Campinas. Campinas, 2007. 178 f. Tese (Doutorado em Ciências) - Universidade Estadual de Campinas, Campinas, 2007.

PREFEITURA MUNICIPAL DE CAMPINAS. Plano Municipal de Habitação de Campinas.Campinas: Prefeitura Municipal de Campinas; Secretaria de Habitação, 2011.
ROLNIK, R. A Construção de Uma Política Fundiária e de Planejamento Urbano Para o País: avanços e desafios. In: INSTITUTO DE EPSQUISAS ECONÔMICAS APLICADAS.Políticas Sociais, Acompanhamento e Análise.Brasília: IPEA, 2006. p. 199-210.

ROLNIK, R.(Org.). Como Produzir Moradia Bem Localizada Com os Recursos Programa Minha Casa, Minha Vida? Implementando os instrumentos do Estatuto da Cidade. Brasília: Ministério das Cidades, 2010.

ROLNIK, R.; CYMBALISTA, R.; NAKANO, K. Solo Urbano e Habitação de Interesse Social: a questão fundiária na política habitacional e urbana do país. 2008. Disponível em:

<http://raquelrolnik.files.wordpress.com/2013/04/s olo-urbano-e-his-rolnik-nakano-cymbalista.pdf $>$. Acesso em: 23 maio 2014.

SANTOS JUNIOR, O. A. dos; MONTANDON, D. T. (Orgs.). Os Planos Diretores Municipais Pós-Estatuto da Cidade: balanço crítico e perspectivas. Rio de Janeiro: Letra Capital; Observatório das Metrópoles, 2011.

SILVA, H. M. M. B. Terra e Moradia: que papel para o município? São Paulo, 1997. 260 f. Tese (Doutorado em Arquitetura e Urbanismo) Universidade de São Paulo, São Paulo, 1997.

SILVA, J. M. P. Investigação Sobre Relações Entre Investimento Público em Habitação de Interesse Social e o Planejamento Territorial: municípios da Região Metropolitana de Campinas. In: CONGRESSO INTERNACIONAL: SUSTENTABILIDADE E HABITAÇÃO DE INTERESSE SOCIAL CHIS, 2., Porto Alegre, 2012.Anais...Porto Alegre: EdiPUCRJ, 2012.

VALENÇA, M. M.; BONATES, M. F. The Trajectory of Social Housing Policy in Brazil: from the National Housing Bank to the Ministry of the Cities. Habitat International, p. 165173,2010 .

\section{Agradecimento}

Agradecemos ao apoio da Fundação de Amparo à Pesquisa do Estado de São Paulo (Fapesp). 
Joana Aparecida Zavaglia Mascarenhas Torres Ribeiro

Programa de Pós-Graduação em Urbanismo, Centro de Ciências Exatas, Ambientais e de Tecnologias | Pontifícia Universidade Católica de Campinas | Rod. Dom Pedro I, km 136, Parque das Universidades | Campinas - SP - Brasil | CEP 13086-900 | Tel.: (19) 3343-7088 |

E-mail: joana.zavagliaribeiro@gmail.com

\section{Tomás Antonio Moreira}

Instituto de Arquitetura e Urbanismo | Universidade de São Paulo | Av. Trabalhador Sancarlense, Parque Arnold Schimidt | São Carlos - SP - Brasil | CEP 13566-590 | Tel.: (16) 3373-9311 | E-mail: tomas_moreira@hotmail.com

\section{Revista Ambiente Construído}

Associação Nacional de Tecnologia do Ambiente Construído

Av. Osvaldo Aranha, $99-3^{\circ}$ andar, Centro

Porto Alegre - RS - Brasil

CEP 90035-190

Telefone: +55 (51) 3308-4084

Fax: +55 (51) 3308-4054

www.seer.ufrgs.br/ambienteconstruido

E-mail: ambienteconstruido@ufrgs.br 